\title{
BMJ Open Psychosocial work demands and physical workload decrease with ageing in blue-collar and white-collar workers: a prospective study based on the SLOSH cohort
}

\author{
Torbjörn Åkerstedt, ${ }^{\oplus 1,2}$ Andrea Discacciati, ${ }^{3}$ Henrike Häbel, ${ }^{3}$ Hugo Westerlund ${ }^{2}$
}

To cite: Åkerstedt T,

Discacciati A, Häbel $\mathrm{H}$, et al. Psychosocial work demands and physical workload decrease with ageing in blue-collar and white-collar workers: a prospective study based on the SLOSH cohort. BMJ Open 2019;9:e030918. doi:10.1136/ bmjopen-2019-030918

- Prepublication history for this paper is available online. To view these files, please visit the journal online (http://dx.doi org/10.1136/bmjopen-2019030918).

Received 07 April 2019 Revised 10 July 2019 Accepted 21 August 2019

Check for updates

(C) Author(s) (or their employer(s)) 2019. Re-use permitted under CC BY-NC. No commercial re-use. See rights and permissions. Published by BMJ.

${ }^{1}$ Department of Clinical Neuroscience, Karolinska Institutet, Stockholm, Sweden ${ }^{2}$ Stress Research Institute, Stockholm University, Stockholm, Sweden

${ }^{3}$ Institute of Environmental Medicine, Karolinska Institute, Stockholm, Sweden

Correspondence to Dr Torbjörn Åkerstedt; Torbjorn.Akerstedt@ki.se

\section{ABSTRACT}

Objectives Psychosocial work demands and physical workload are important causes of ill health. The dramatic demographic changes in society make it important to understand if such factors change with ageing, but this is presently not known. The purpose of the present study was to investigate whether psychosocial work demands and physical workload change across 8 years of ageing, whether occupational groups show different trajectories of change and if such trajectories are reflected in sleep or fatigue.

Methods A cohort of 5377 participants (mean age: $47.6 \pm 11.6$ (SD) years, $43.2 \%$ males, $40.2 \%$ blue-collar workers) was measured through self-report in five biannual waves across 8 years. Mixed model regression analyses was used to investigate change across ageing.

Results Psychosocial work demands decreased significantly across 8 years (Coeff: $-0.016 \pm 0.001$ ), with the strongest decrease in the high white-collar group (Coeff $=-0.031 \pm 0.003$ ) and the oldest group. Physical workload also decreased significantly (Coeff $=-0.032 \pm 0.002)$, particularly in the blue-collar group (Coeff $=-0.050 \pm 0.004$ ) and in the oldest group. Fatigue decreased, and sleep problems increased with ageing, but with similar slopes in the occupational groups. All effect sizes were small, but extrapolation suggests substantial decreases across a working life career. Conclusions The decrease in psychosocial work demands and physical workload suggests that the burden of work becomes somewhat lighter over 8 years. The mechanism could be 'pure' ageing and/or increased experience or related factors. The gradual improvement in the work situation should be considered in the discussion of the place of older individuals in the labour market, and of a suitable age for retirement. The results also mean that prospective studies of work and health need to consider the improvement in working life with ageing.

\section{INTRODUCTION}

Psychosocial work demands are a central factor in research on occupational stress ${ }^{12}$ that is associated with cardiovascular and other diseases. ${ }^{3}$ It involves a need to work fast, to handle difficult tasks or to have too little time
Strength and limitations of this study

- A strength of this study is the longitudinal approach and relatively large sample size.

- A limitation is the subjective nature of the data, although both main variables are, by nature, subjective.

- Another limitation is that we cannot determine the mechanism behind the decreases with ageing.

- A third limitation is that generalisation is difficult beyond the North-Western European labour market.

for one's tasks. There is also a prospective link between work demands and disturbed sleep $^{4-7}$ and with fatigue. ${ }^{8}$ Sleep problems, in turn, predict a high utilisation of healthcare resources ${ }^{10}$ and sickness absence. ${ }^{11}$ Fatigue is associated with similar effects. ${ }^{12-14}$ The link between psychosocial work demands and health, sleep and fatigue is usually seen as a stress reaction with increased physiological and mental arousal due to attempts to handle the demands. ${ }^{3}$

Considering the increasing proportion of elderly in society it is an interesting question whether psychosocial work demands increase or decrease with ageing. There are no previous studies on this issue, but there is a need to provide knowledge for the discussion of working life sustainability, and the feasibility of a later retirement age. For lack of empirical data one might entertain two hypotheses. Thus, one might assume that ageing may lead to more responsibility and, thus, a higher load of psychosocial work demands. Also the opposite could be true, since ageing is associated with increased experience, which could increase the capacity to handle demands. The latter may well be perceived as a reduction of demands. 
If there are changes in psychosocial work demands with ageing, the patterns are likely to be different for blue-collar workers (BCW) and white-collar workers. The demands are higher among white-collar workers and one may speculate that changes with time might be larger in that group. ${ }^{1516}$

Since psychosocial work demands are linked to (poor) sleep and to fatigue, one might expect these variables to reflect changes in work demands, that is, trajectories across ageing should be correlated. There are no such data available, but we have seen that fatigue actually decreases with ageing, whereas sleep problems increase moderately. ${ }^{17}$ One would also expect trajectories of sleep and fatigue to reflect any differences in trajectories in psychosocial work demands between occupational groups.

Another work-related factor that should be considered in connection with psychosocial work demands is physical workload. It is particularly associated not only with musculoskeletal pain ${ }^{18}{ }^{19}$ but also with cardiovascular disease, ${ }^{2021}$ as well as with fatigue. ${ }^{22}$ It is, for obvious reasons, highest in BCW. As to the effects of ageing, the reasoning is similar to that for psychosocial work demands, but no longitudinal studies are available. With respect to sleep, one study failed to find a longitudinal association between physical work demands and sleep, ${ }^{7}$ but very little work has been done in this area. Fatigue, in contrast, is well established as an outcome of physical workload. ${ }^{23}$ One would expect that the trajectories of the two variables are correlated and that any differences between occupational groups in physical workload would be reflected in corresponding differences in fatigue.

The purpose of the present study was to investigate whether work demands and physical workload change across 8 years, whether occupational groups show different trajectories of change and if such trajectories are reflected in trajectories of sleep or fatigue. Specific hypotheses are difficult to develop since ageing involves reduced physical and cognitive work capacity ${ }^{24}$ that should be linked to a perception of increased demands or workload, while increased work experience and career changes may be counterforces.

\section{METHODS}

\section{Design and participants}

The study was based on the Swedish Longitudinal Occupational Survey of Health (SLOSH). It is a nationally representative longitudinal cohort survey of at entry (T0) gainfully employed individuals in the age range of 16-64 years, from the entire country, stratified by county, sex and citizenship. ${ }^{26}$ Participants have been followed up by postal questionnaires every 2 years, since 2006 . This survey has its origins in the Swedish Work Environment Survey (www. scb.se), which, in turn, is based on nationally representative samples of the working population. In the present paper, we use data from waves 1 to 5 (T1-T5), including only individuals employed at the start of follow-up (T1) and with available information on occupational group (from T2). This resulted in 5377 participants.

The sample at $\mathrm{T} 1$ contained $43.2 \%$ males; $33.9 \%$ aged $18-42$ years, $42.1 \%$ aged $43-56$ years and $24.1 \%$ aged 57-68 years; $55.3 \%$ married; $53.4 \%$ with children (living at home) and $80.2 \%$ in very or rather good health. Mean age $\pm \mathrm{SD}$ was $47.6 \pm 11.6$ years; $3.5 \%$ were not working. The latter were removed from the analyses.

\section{Variables}

Information regarding gender, age and occupational category (BCW, white-collar workers and managers) were derived from self-report at T2. The occupational categories are based on the Statistics Sweden official classification of occupations to produce the categories BCW, lower white-collar workers (LWC) and professionals and managers (high white-collar workers (HWC)). The $\mathrm{N}$ for the three groups was 2163, 2226 and 988, respectively.

Work demands were measured using the Swedish version of the Demand-Control-Support Questionnaire. ${ }^{1}$ This scale has been extensively psychometrically investigated $^{227}$ and used to predict health outcomes of psychosocial work factors. ${ }^{28}{ }^{29}$ The five items used were: 'Do you have to work very intensively?', 'Does your work demand too much effort?', 'Do you have enough time to do everything?' (reverse coded), 'Do you have to work very fast?' and 'Does your work often involve conflicting demands?'. The response alternatives ranged from 1: hardly ever/ never to 4: yes, often (scaled reversed from the original 4-1). Cronbach's $\alpha$ was 0.67 at T3.

Four items representing disturbed sleep were selected from the Karolinska Sleep Questionnaire (KSQ) (Cronbach's alpha>0.70). ${ }^{50-32}$ The scale differentiates patients with insomnia from healthy individuals ${ }^{31}$ and correlates with perceived stress, anxiety, depression and burnout $(r>0.40) .{ }^{32}$ The items included are difficulties falling asleep, restless sleep, repeated awakenings and premature awakening. The responses range from 'never' to 'most days of the week' (1-6). Cronbach's alpha was 0.84 at time T3 and the correlation between time points was $\mathrm{r}=0.71$.

Ratings of fatigue were obtained from a single item phrased as 'to what extent have you been suffering from sluggishness or lack of energy', with response alternatives from 1 (not at all) to 5 (very much). It is significantly correlated $(\mathrm{r}=0.60, \mathrm{p}<0.001)$ with persistent fatigue and mental fatigue $(\mathrm{r}=0.57, \mathrm{p}<0.001)$ at $\mathrm{T} 3$.

Physical workload was measured as an index of three questions: 'Is your work such that you have to use bent, twisted or otherwise unsuitable positions?', 'Do you have to lift at least 15 kilos several times a day?' and 'Does your work sometimes involve heavy physical labour, that is, do you physically exert yourself more than when walking and standing and moving around in a normal way?'. Response alternatives ranged from 1: no, not at all to 6: almost all the time. Cronbach's $\alpha$ was 0.89 for at T1, and the testretest reliability between $\mathrm{T} 1$ and $\mathrm{T} 2$ was $\mathrm{r}=0.85$. 


\section{Statistical analysis}

To describe the mean trajectories of the outcomes over time (waves T1-T5) for different occupational groups we used mixed-effects linear regression models. ${ }^{33}$ Regression models included occupational group (level-2 variable), individual (across time) (level-1 variable) and their two interaction (product) terms as fixed effects. Moreover, they included subject-specific random intercept and time slope to account for potential dependence among repeated values of the outcome variables over time. The analyses were adjusted for gender and age (level-2 variables). The overall difference in the slopes over time across the three occupational groups was assessed with a joint Wald test with two degrees of freedom on the two interaction terms. Waves when an individual was not employed were not used in the analyses. Effect size was computed as the coefficient of the slope divided by the within-subject SD, as suggested in https://www.ncbi.nlm. nih.gov/pmc/articles/PMC3743548/\#FD8.

In a second analysis, the subject-specific time slopes for work demands and physical workload were used as predictors for the other outcomes. More specifically, we first modelled work demands and physical workload using two mixed-effects linear regression models. These models included time as fixed effect with random intercept and slope. We then calculated subject-specific slopes by adding to the fixed-effects time coefficient the subject-specific best linear unbiased predictions of the random slope. Finally, we used the subject-specific slopes as a fixed-effect in a separate mixed-effects linear regression model, adjusted for age and gender, with random intercept and random time slope.

In a third analysis, we described the age group-specific mean trajectories of the outcomes over time. This was done in an analogous fashion to what we described for the main analysis. Age groups were defined as: 18-42, $43-56$ and 57-68 years of age. This was also repeated with stratification within each occupational group.

\section{Patient and public involvement statement}

Patients were not involved in the present study.

\section{RESULTS}

The mean values and $\mathrm{SD}$ at $\mathrm{T} 1$ for the four main variables were: $2.67 \pm 0.58$ for psychosocial work demands, $2.38 \pm 1.56$ for physical workload, $2.47 \pm 1.06$ for sleep problems and $2.26 \pm 1.09$ for fatigue. Medians for the four variables were: $2.75,1.67,2,25$ and 2.00 , respectively.

Figure 1 and table 1 show the effects of ageing on self-reported work demands. The decrease across time was significant for the total sample and for each group separately. For reference, the decrease in the total sample, represented by the coefficient -0.016 , corresponds to a change of -0.08 units on the $1-4$ unit scale across 8 years. The interaction between the occupational groups was highly significant, that is, the three groups showed different slopes over time, with the largest slope (and effect size)

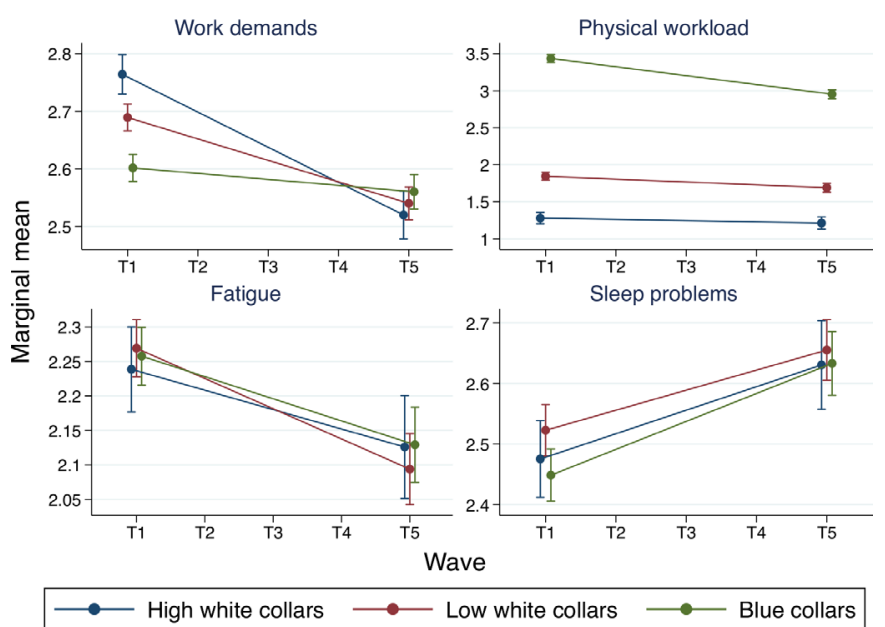

Figure 1 Trajectories of work demands, physical workload, sleep quality, fatigue, sleep duration weekdays and sleep duration weekends in three occupational groups. Mean predicted outcomes at T1 and T5, marginalised over the age and gender distribution at T1.

for HWC, for which the coefficient -0.031 corresponds to -0.15 units on a $1-6$ point scale across 8 years.

In addition, BCW showed (at T3) lower demands than HWC $(0.06 \pm 0.02, Z=3.2, p=0.000)$, but LWC did not $(-0.03 \pm 0.02, \mathrm{Z}=1.5, \mathrm{p}=0.147)$. Women showed higher values (higher demands) than men $(0.05 \pm 01, \mathrm{Z}=3.5$, $\mathrm{p}=0.000)$. The oldest group showed significantly lower work demands $(0.14 \pm 0.02, \mathrm{Z}=7.8, \mathrm{p}=0.000)$ than the youngest group, but the intermediate group did not $(0.02 \pm 0.01, \mathrm{Z}=1.4, \mathrm{p}=0.147)$.

Figure 1 shows the effects of ageing on physical workload in the three occupational groups. Table 1 shows that the decrease in workload was significant for the total sample. The coefficient for the total sample $(-0.033)$ corresponds to a decrease of -0.16 units (scale $=1-6$ ) across the 8 years. The interaction between groups was highly significant, with the largest coefficient (and effect size) for BCW ( -0.05 units across the five waves), corresponding to a decrease of 0.25 units across the 8 years.

BCW showed (at T3) a significantly higher physical workload than HWC $(1.948 \pm 0.044, \mathrm{Z}=44.5, \mathrm{p}=0.000)$, which also LWC did $(0.521 \pm 0.044, \mathrm{Z}=11.9, \mathrm{p}=0.000)$. Women showed higher physical workload than men $0.145 \pm 0.032, \mathrm{Z}=4.6, \mathrm{p}=0.000)$. The oldest group showed significantly lower physical load $(0.115 \pm 0.041, \mathrm{Z}=2.8$, $\mathrm{p}=0.006$ ) than the youngest group.

Figure 1 shows the effect of ageing on fatigue in the three occupational groups. Table 1 shows that the reduction in fatigue was significant for the total group and each occupational group. The interaction was not significant and the level between groups did not differ significantly. However, at T3, women had a significantly higher level of fatigue $(0.25 \pm 0.02, \mathrm{Z}=10.4, \mathrm{p}=0.000)$. In addition, older individuals showed significantly less fatigue $(-0.37 \pm 0.03$, $\mathrm{Z}=11.7, \mathrm{p}=0.000)$ than the young group. The intermediate age group also showed lower fatigue $(-0.16 \pm 0.03$, $\mathrm{Z}=5.9, \mathrm{p}=0.000$ ). 


\begin{tabular}{|c|c|c|c|c|c|c|}
\hline Occupational groups & Coeff \pm SE & $\mathbf{z} \chi^{2}$ & Effect size & Coeff \pm SE & $\mathbf{z} \chi^{2}$ & Effect size \\
\hline & Work demands & & & Physical worklo & & \\
\hline All & $-0.016 \pm 0.001$ & $12.2^{\star \star \star}$ & 0.043 & $-0.033 \pm 0.002$ & $14.3^{\star \star \star}$ & 0.057 \\
\hline HWC & $-0.031 \pm 0.003$ & $10.6^{\star \star \star}$ & 0.084 & $-0.008 \pm 0.005$ & 1.7 & 0.014 \\
\hline LWC & $-0.029 \pm 0.002$ & $9.4^{\star \star \star}$ & 0.078 & $-0.019 \pm 0.003$ & $5.5^{\star \star \star *}$ & 0.033 \\
\hline BCW & $-0.005 \pm 0.002$ & $2.5^{\star}$ & 0.014 & $-0.050 \pm 0.004$ & $16.3^{\star \star \star}$ & 0.087 \\
\hline \multirow[t]{2}{*}{ Interaction $\chi^{2}$} & & $53.5^{\star \star \star}$ & & & $94.0^{\star \star \star}$ & \\
\hline & Fatigue_rec & & & Sleep problems & & \\
\hline All, & $-0.018 \pm 0.002$ & $7.5^{\star \star \star}$ & 0.022 & $0.020 \pm 0.002$ & $9.4^{\star \star \star}$ & 0.033 \\
\hline HWC & $-0.014 \pm 0.005$ & $2.6^{*}$ & 0.017 & $0.019 \pm 0.005$ & $4.2^{*}$ & 0.032 \\
\hline LWC & $-0,022 \pm 0.004$ & $5.9^{\star \star \star}$ & 0.027 & $0.017 \pm 0.003$ & $5.2^{\star \star \star}$ & 0.028 \\
\hline BCW & $-0.016 \pm 0.004$ & $4.1^{*}$ & 0.020 & $0.023 \pm 0.003$ & $6.8^{\star \star \star}$ & 0.038 \\
\hline Interaction $\chi^{2}$ & & 1.9 & & & 2.0 & \\
\hline
\end{tabular}

Coefficients of slope, SE, Z-value, $p$-value. $\chi^{2}$ value for interaction and effect sizes; $n=5377 .{ }^{*} P<0.05 ;{ }^{* * *} P<0.001$

$\mathrm{BCW}$, blue-collar workers; HWC, high white-collar workers; LWC, low white-collar workers.

Figure 1 shows the effects of ageing on sleep problems in the three occupational groups. Table 1 shows that the increase in sleep problems was significant for the total group, as well as in all three occupational groups. The interaction was not significant and the level between groups did not differ significantly. At T3, women reported more sleep problems than men $(0.28 \pm 0.03, \mathrm{Z}=10.8$, $\mathrm{p}=0.000)$. The oldest individuals reported more sleep problems than the young $(0.07 \pm 0.03, \mathrm{Z}=2.17, \mathrm{p}=0.03)$, as did the intermediate group $0.17 \pm 0.03(\mathrm{Z}=5.9, \mathrm{p}=0.000)$.

As a sensitivity analysis, we repeated the previous analyses for those participants who had complete data for all five waves $(n=1888)$. The results were very similar to the previous results. The only difference was that the significant decrease in work demands for BCW $(p<0.05)$ and the significant decrease in fatigue for HWC $(p<0.05)$ did not remain significant.

To test the direct association of changes between work demands and the other variables, we used a mixed-model regression and computed the relation between the individual slopes in work demands and in the other variables. Table 2 shows significant positive regression coefficients for all analyses. Note that the regression is computed between subject-specific slopes. Thus, the positive regression coefficient between psychosocial work demands and sleep problems means that steep decreases in work demands (constituting negative values of the slope for that variable) are associated with decreases, or low increases, in sleep problems (low values of the slope for that variable). Positive regression coefficients were seen also between physical workload and fatigue.

Since there is a possibility that the change across time in the main analysis might be different in different age groups, we also analysed the trajectories within three age groups: $18-42$ years, $42-56$ years and 57-68 years, adjusted for gender. Table 3 shows a strong interaction between work demands and age groups, with the largest decrease (and effect size) in the oldest group, although all three trajectories were significant. For physical workload, the trajectories of each age group was significant, but the interaction was not.

There was a similar pattern for fatigue and sleep problems. In both cases, the interaction was significant. For fatigue, the oldest group showed the strongest decrease (and effect size), whereas for sleep problems, the youngest group showed the strongest increase (and effect size), while the oldest group showed a significant decrease. In all cases, the decrease was largest in the oldest group. For sleep problems, the interaction between age groups was significant, but here the oldest group had the smallest decrease.

The same analysis subdivided on occupational group showed similar results. For work demands, the interaction

Table 2 The regression of the slopes of work demands and physical workload versus the slopes of fatigue and sleep problems (mixed-model regression)

\begin{tabular}{llcllll}
\hline & $\begin{array}{l}\text { Work demands } \\
\text { versus } \\
\text { Coeff } \pm \text { SE }\end{array}$ & $\mathbf{Z}$ & P value & $\begin{array}{l}\text { Physical workload } \\
\text { versus } \\
\text { Coeff } \pm \text { SE }\end{array}$ & Z & P value \\
\hline Physical workolad & $0.204 \pm 0.031$ & 6.5 & 0.000 & & & \\
Fatigue & $0.106 \pm 0.010$ & 10.9 & 0.000 & $0.010 \pm 0.004$ & 2.4 & 0.018 \\
Sleep problems & $0.243 \pm 0.022$ & 11.1 & 0.000 & $0.028 \pm 0.010$ & 2.9 & 0.004 \\
\hline
\end{tabular}

Adjusted for age and gender. ${ }^{\star} \mathrm{P}<0.05 ;{ }^{\star \star} \mathrm{P}<0.01$; ${ }^{\star \star \star} \mathrm{P}<0.001$. 
Table 3 Trajectories across 8 years of work demands, physical workload, fatigue and sleep problems for three age groups for the full group and for each occupational group, adjusted for gender

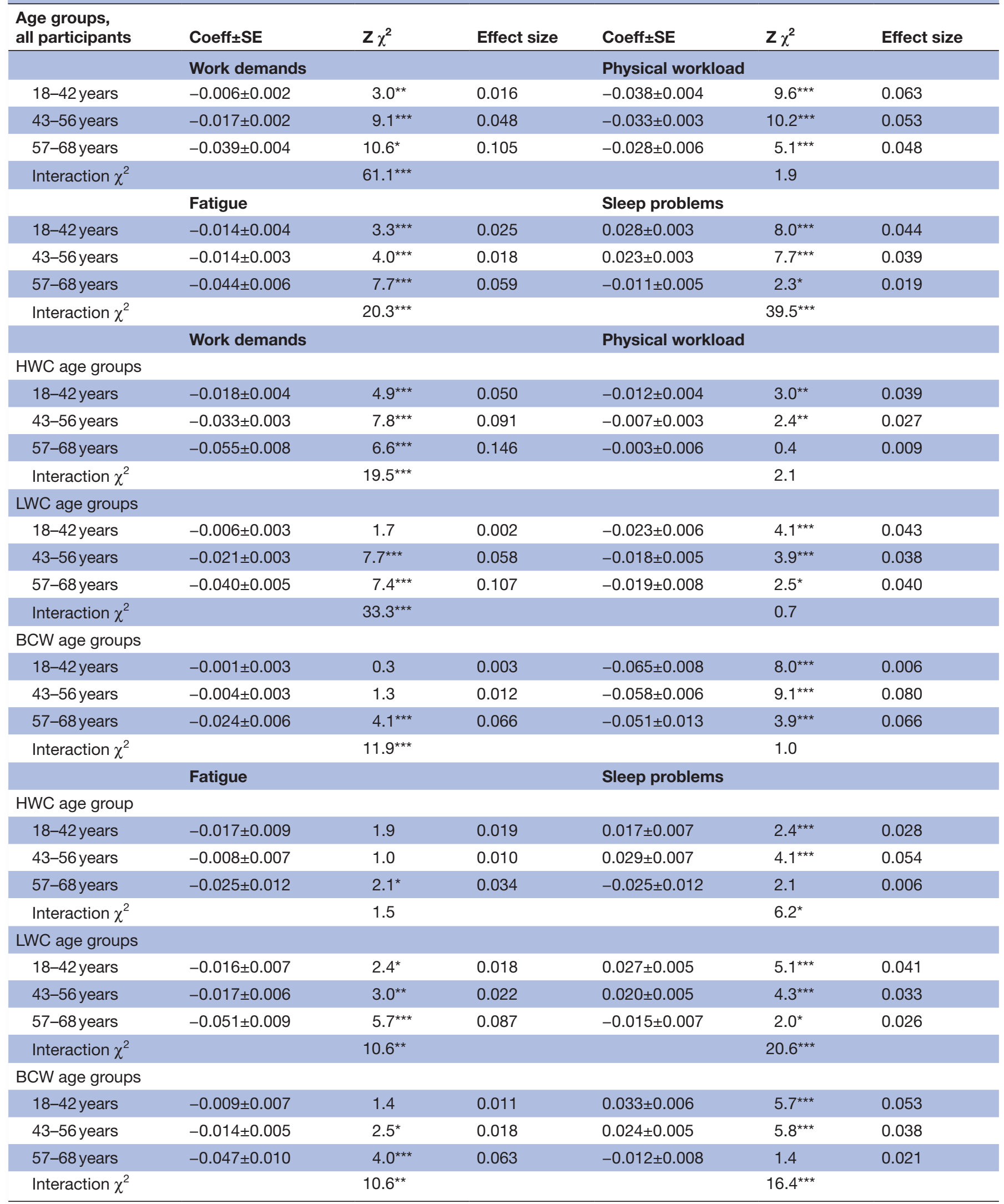

${ }^{*} \mathrm{P}<0.05 ;{ }^{\star \star} \mathrm{P}<0.01 ;{ }^{* \star *} \mathrm{P}<0.001$.

$\mathrm{BCW}$, blue-collar workers; HWC, high white collar workers; LWC, low white collar workers. 
between time and age group was significant in all three occupational groups and the decrease strongest in the oldest group. For physical work demands, no significant interactions were obtained. For fatigue, the interaction was significant in the LWC and BWC groups, with the strongest decrease in the oldest group. For sleep problems, all three occupational groups showed significant interactions, with the lowest increase in the oldest group.

\section{DISCUSSION}

Not only the work demands decreased significantly within individuals over time in all three occupational groups but also the interaction was highly significant. The steepest decrease was seen in HWC. The latter group also showed the overall highest level of work demands. Physical workload showed a decrease for the BCW and LWC groups and a significant interaction across occupational groups, with BCW showing the highest mean level. The changes in both variables were strongest in the oldest group. Sleep problems increased and fatigue decreased in all three occupational groups, but there was no interaction between groups. There was also a significant association between the decreased work demands and sleep and fatigue variables. For physical workload, the associations were weaker.

The effect size of the decrease in psychosocial work demands is relatively small. However, considering the change across a working life career of 40 years, the decrease corresponds to a reduction of 0.4 units for the total group and 0.75 for HWC. This represents 2/3 of the SD of the present sample. The implications of such a change are not straightforward to evaluate since most studies of psychosocial work demands seldom report scale values in relation to health. They rather present results after dichotomisation of scale values into high and low demands. The dichotomisation is usually made at the median or highest quartile to identify 'high' demands. However, in a study of psychosocial work demands and musculoskeletal problems, scale values were presented (mean $\pm \mathrm{SD}=2.42 \pm 0.54$ units) with a cut-off for high demands at the 67 th percentile $=3.04$ units, and with intermediate level (median) cut-off at 2.40 units. Thus, using our results, a person at an intermediate level of demands $(\approx 2.72)$ would be expected to change into the low demand category (at 2.32 units) from the beginning to the end of working life, as long as the extrapolation of the 8 years coefficients may be assumed to be linear. White-collar workers would be expected to change about twice as much. Thus, it seems that the decrease in psychosocial work demands with age/experience should have practical implications, particularly for HWC.

The improvement in work demands across time should be a positive finding for individuals in situations with high psychosocial work demands. The results should have implications for discussions of a sustainable working life and of a reasonable retirement age. In addition, the results have implications for the interpretation of results of prospective research studies, since a long follow-up time would mean a lower exposure to work demands across time, leading to a likely attenuation of the effects of high work demand levels on later disease outcomes.

We are not able to determine the reason for the decrease in work demands, but it is likely that increased experience with ageing makes the individual more competent at handling work tasks. Ageing was also associated with reduction in fatigue, which might contribute. It is also likely that the possibility to step down increases with increasing age, and career motives may become less salient; both may reduce perceived psychosocial work demands. The suggested causes discussed here clearly need increased research efforts.

The difference in steepness in the decrease of work demands in the three occupational groups could possibly be interpreted as differences in the positive effects of work experience. Professional groups and managers usually have more complex work tasks for which experience may have more dramatic effects on mastery than what may be the cases for BCW. In addition, professional groups may have better possibilities to step down from responsibilities than workers. Again, these notions need further research.

The decrease in physical workload also seems to be a new finding, and we lack data to compare with. Even if the effect size was modest, one might, again, consider the size of the decrease across 40 years of work, which amounts to approximately 0.8 units, if linear extrapolation is permissible. One might compare this with results from a study using the same items for physical load to predict lower back pain. ${ }^{34}$ This study set values of $1-3$ as 'no exposure', 4 as intermediate and $5+6$ as high exposure (with significant prediction of back pain for both exposed groups). A decrease of 0.8 units across a working life career would then bring many highly exposed individuals into the intermediate exposure category and those with intermediate exposure into the unexposed category. Thus, the estimated reduction in physical workload across a working life career appears considerable.

The difference in steepness in the decrease of physical workload in the three occupational groups probably partly reflects the fact that most white-collar workers have low levels of physical workload from the start. As with the decrease in psychosocial work demands in HWC, one could speculate that experience may increase the physical capacity and perhaps the skill to handle physical workload in BCW. One might also conceive of experience leading to a move to work tasks with less physical load. These lines of reasoning are speculation, however, and there is a need for studies on how age itself, experience at work, move to another job, improvement in work tasks and similar factors lead to a perception of a reduced physical workload. Note that the coefficient for BCW is approximately $50 \%$ larger than that of the total group. This suggests that the decrease across a working life career should have implications for the ability to sustain a long working life for BCW.

As expected, the individual slopes of the decrease in work demands were associated with a decrease in fatigue, 
as well as a lower increase in sleep problems (or even a decrease). This is in line with the day-to-day association between the three variables in a diary study across 42 days ${ }^{35}$ and strengthens the notion of a link between work demands and sleep quality, as well as with fatigue.

The similar slope of sleep problems and fatigue for all occupational groups failed to reflect the different trajectories for psychosocial work demands and physical workload for those groups. This was unexpected, particularly since at least psychosocial work demands have been linked to fatigue and sleep problems in previous studies ${ }^{176}$ and since the present data (table 2) shows clear associations between work demands and sleep problems on the individual level.

The age-related difference in trajectories of the decrease in work demands does not have an obvious explanation. All participants were still employed at the last point of measurement, so formal retirement does not seem to be implicated as a cause. However, work hours could have been reduced, which is in line with the decrease being largest in the oldest group, and reduced work hours are associated with reduced demands. ${ }^{37}$ We lack specific information on work hours in the present study, however. The fact that the reduction of psychosocial work demands in the present study was significant also in the middle age group suggests that reduced work hours should not have been the only cause, since part-time work is unusual in that group. This is also supported by the significant decrease also in the youngest group. Another, probably important, factor should be the effect of experience on the ability to handle work demands, and possibly, also the effect of promotion to positions with more control over the work situation. Furthermore, loss of, particularly, physical work capacity might result in transfer to less demanding work tasks. However, the present study did not contain variables that make it possible to judge effects of increased experience, promotion or change of work tasks.

The reduction of fatigue with time agrees with findings of lower fatigue in older individuals. ${ }^{38}$ The observation that the effect was largest in the oldest group is a new observation, but the mechanism may be the same as discussed for work demands above. Sleep problems showed a similar trajectory as fatigue, although here the oldest group lacked the impairment over time that the younger groups had. Previous work has consistently found sleep problems to increase with age, but there is no previous data on the lack of increase in sleep problems in older individuals across time, except for our own previous study on the same material. ${ }^{17}$ The same factors as discussed above may be invoked also in this case, but there may also be effects of biological ageing.

The decrease of psychosocial work demands and physical workload across time leaves a positive impression of the ageing process in working life. Work appears to become easier with time. The observation that the effect is largest in the oldest groups indicates that from this point of view, working life is sustainable. It also indicates that a temporal extension of working life could well be acceptable to many individuals, at least those still in good health. This is further accentuated by the reduction of fatigue with time. It is an interesting question for future work to determine if the observed improvement in psychosocial work demands and physical workload also leads to improved productivity.

There are some limitations to the present study. First, all data are subjective, but this is difficult to avoid since objective measures of the variables is difficult with $>5000$ participants. Another limitation is that there was a substantial loss of participants across time, possibly indicating a healthy worker effect. However, an analysis of the completers did not change the results appreciably. Among the dropouts, there are probably individuals who died. This would have been interesting information to analyse, but unfortunately we did not have access to such data. With the present analysis, we cannot draw any conclusions regarding causation but that was not the purpose of the study. Rather, the purpose was to study whether ageing or time at work would affect work demands and that steered the analysis towards the approach of evaluating slopes over time. The strength of the study is the longitudinal approach, which makes it possible to evaluate the effects of time.

\section{CONCLUSION}

The results indicate that psychosocial work demands and physical workload decrease with time, which may have implications for discussions of a sustainable working life and of a temporal extension of working life. The study has some limitations and there is need for replication in studies with objective measures.

Contributors TÅ defined the research question, designed the study and wrote the draft. $A D$ analysed the data and commented on the manuscript. HW provided the cohort and commented on the manuscript. HH provided statistical advice and commented on the manuscript.

Funding This work was supported by the AFA Insurance Company.

Competing interests None declared.

Patient consent for publication Not required.

Ethics approval The Regional Research Ethics Board in Stockholm approved this study.

Provenance and peer review Not commissioned; externally peer reviewed.

Data availability statement Data are available upon reasonable request. This includes application to ethical committee.

Open access This is an open access article distributed in accordance with the Creative Commons Attribution Non Commercial (CC BY-NC 4.0) license, which permits others to distribute, remix, adapt, build upon this work non-commercially, and license their derivative works on different terms, provided the original work is properly cited, appropriate credit is given, any changes made indicated, and the use is non-commercial. See: http://creativecommons.org/licenses/by-nc/4.0/.

\section{REFERENCES}

1. Theorell T, Perski A, Åkerstedt T, et al. Changes in job strain in relation to changes in physiological state. A longitudinal study. Scand $J$ Work Environ Health 1988;14:189-96.

2. Fransson El, Nyberg ST, Heikkilä K, et al. Comparison of alternative versions of the job demand-control scales in 17 European cohort studies: the IPD-Work Consortium. BMC Public Health 2012;12:62. 
3. Kivimäki M, Steptoe A. Effects of stress on the development and progression of cardiovascular disease. Nat Rev Cardiol 2018;15:215-29.

4. de Lange $\mathrm{AH}$, Kompier MAJ, Taris TW, et al. A hard day's night: a longitudinal study on the relationships among job demands and job control, sleep quality and fatigue. J Sleep Res 2009;18:374-83.

5. Åkerstedt T, Nordin M, Alfredsson L, et al. Predicting changes in sleep complaints from baseline values and changes in work demands, work control, and work preoccupation--the WOLF-project. Sleep Med 2012;13:73-80.

6. Magnusson Hanson LL, Åkerstedt T, Näswall K, et al. Cross-Lagged relationships between workplace demands, control, support, and sleep problems. Sleep 2011;34:1403-10.

7. Åkerstedt T, Garefelt J, Richter A, et al. Work and sleep--a prospective study of psychosocial work factors, physical work factors, and work scheduling. Sleep 2015;38:1129-36.

8. Maslach C, Leiter MP. Stress and burnout: the critical research. In: Cooper CL, ed. Handbook of stress medicine and health. Lancaster, UK: CRC Press, 2005: 155-72.

9. Avlund K. Fatigue in older adults: an early indicator of the aging process? Aging Clin Exp Res 2010;22:100-15.

10. Kuppermann M, Lubeck DP, Mazonson PD, et al. Sleep problems and their correlates in a working population. J Gen Intern Med 1995;10:25-32.

11. Lallukka T, Haaramo $\mathrm{P}, \mathrm{Rahkonen} \mathrm{O}$, et al. Joint associations of sleep duration and insomnia symptoms with subsequent sickness absence: the Helsinki health study. Scand J Public Health 2013;41:516-23.

12. Watt T, Groenvold M, Bjorner JB, et al. Fatigue in the Danish general population. Influence of sociodemographic factors and disease. $J$ Epidemiol Community Health 2000;54:827-33.

13. Janssen Net al. Fatigue as a predictor of sickness absence: results from the Maastricht cohort study on fatigue at work. Occup Environ Med 2003;60(>90001):71i-6.

14. Akerstedt T, Kecklund G, Alfredsson L, et al. Predicting longterm sickness absence from sleep and fatigue. J Sleep Res 2007:16:341-5

15. Hallqvist J, Diderichsen F, Theorell T, et al. Is the effect of job strain on myocardial infarction risk due to interaction between high psychological demands and low decision latitude? Results from Stockholm heart epidemiology program (SHEEP). Soc Sci Med 1998:46:1405-15.

16. Johnson JV, Hall EM, Theorell T. Combined effects of job strain and social isolation on cardiovascular disease morbidity and mortality in a random sample of the Swedish male working population. Scand J Work Environ Health 1989;15:271-9.

17. Åkerstedt T, Discacciati A, Miley-Åkerstedt A, et al. Aging and the change in fatigue and sleep - a longitudinal study across 8 years in three age groups. Front Psychol 2018;9:234.

18. Nyman T. Low back and neck-shoulder pain : Work and heritability. Karolinska Institutet, 2008.

19. Widanarko B, Legg S, Devereux J, et al. Interaction between physical and psychosocial risk factors on the presence of neck/shoulder symptoms and its consequences. Ergonomics 2015;58:1507-18.

20. Clays E, Casini A, Van Herck K, et al. Do psychosocial job resources buffer the relation between physical work demands and coronary heart disease? A prospective study among men. Int Arch Occup Environ Health 2016;89:1299-307.

21. Krause N, Brand RJ, Arah OA, et al. Occupational physical activity and 20-year incidence of acute myocardial infarction: results from the Kuopio ischemic heart disease risk factor study. Scand J Work Environ Health 2015;41:124-39.

22. Åhsberg E. Dimensions of fatigue in different working populations. Scand J Psychol 2000;41:231-41.

23. Bláfoss R, Sundstrup E, Jakobsen MD, et al. Physical workload and bodily fatigue after work: cross-sectional study among 5000 workers. Eur J Public Health 2019;10.

24. Ross D. Ageing and work: an overview. Occup Med 2010;60:169-71.

25. Fisher GG, Chaffee DS, Tetrick LE, et al. Cognitive functioning, aging, and work: a review and recommendations for research and practice. $J$ Occup Health Psychol 2017:22:314-36.

26. Magnusson Hanson LL, Leineweber C, Persson V, et al. Cohort profile: the Swedish longitudinal occupational survey of health (SLOSH). Int J Epidemiol 2018.

27. Chungkham HS, Ingre M, Karasek R, et al. Factor structure and longitudinal measurement invariance of the demand control support model: an evidence from the Swedish longitudinal occupational survey of health (SLOSH). PLOS One 2013;8:e70541.

28. Kivimäki M, Nyberg ST, Batty GD, et al. Job strain as a risk factor for coronary heart disease: a collaborative meta-analysis of individual participant data. The Lancet 2012;380:1491-7.

29. Magnusson Hanson LL, Madsen IEH, Westerlund H, et al. Antidepressant use and associations with psychosocial work characteristics. A comparative study of Swedish and Danish gainfully employed. J Affect Disord 2013;149:38-45.

30. Åkerstedt T, Knutsson A, Westerholm P, et al. Sleep disturbances, work stress and work hours: a cross-sectional study. J Psychosom Res 2002;53:741-8.

31. Åkerstedt $\mathrm{T}$, Ingre $\mathrm{M}$, Broman J-E, et al. Disturbed sleep in shift workers, day workers, and insomniacs. Chronobiol Int 2008;25:333-48.

32. Nordin M, Åkerstedt T, Nordin S. Psychometric evaluation and normative data for the Karolinska sleep questionnaire. Sleep Biol Rhythms 2013;11:216-26.

33. Rabe-Hesketh S, Skrondal A. Multilevel and longitudinal modeling using Stata. First Edition. Texas: Stata Press, 2005.

34. Halonen JI, Shiri R, Magnusson Hanson LL, et al. Risk and prognostic factors of low back pain: repeated population-based cohort study in Sweden. Spine 2019;44:1248-55.

35. Åkerstedt T, Axelsson J, Lekander M, et al. Do sleep, stress, and illness explain daily variations in fatigue? A prospective study. $J$ Psychosom Res 2014;76:280-5.

36. Åkerstedt T, Orsini N, Petersen $\mathrm{H}$, et al. Predicting sleep quality from stress and prior sleep--a study of day-to-day covariation across six weeks. Sleep Med 2012;13:674-9.

37. Schiller $\mathrm{H}$, Lekander M, Rajaleid K, et al. The impact of reduced worktime on sleep and perceived stress - a group randomized intervention study using diary data. Scand $J$ Work Environ Health 2017:43:109-16.

38. Dolan P, Kudrna L. More years, less yawns: fresh evidence on tiredness by age and other factors. J Gerontol B Psychol Sci Soc Sci 2015;70:576-80. 